\title{
MS/MS-Guided Isolation of Clarinoside, a New Anti-Inflammatory Pentalogin Derivative
}

\author{
Coralie Audoin ${ }^{1}$, Adam Zampalégré ${ }^{1}$, Natacha Blanchet ${ }^{1}$, Alexandre Giuliani ${ }^{2,3}$ (1), \\ Emmanuel Roulland ${ }^{4}\left(\right.$ (D) , Olivier Laprévote ${ }^{4,5}$ and Grégory Genta-Jouve ${ }^{4, *}$ (i) \\ 1 Laboratoires Clarins, 5 rue Ampère, 95300 Pontoise, France; coralie.audoin@clarins.com (C.A.); \\ adam.zampalegre@clarins.com (A.Z.); natacha.blanchet@clarins.com (N.B.) \\ 2 DISCO Beamline, Synchrotron SOLEIL, 91192 Gif-sur-Yvette, France; \\ alexandre.giuliani@synchrotron-soleil.fr \\ 3 UAR1008, CEPIA, INRA, 44316 Nantes, France \\ 4 C-TAC, UMR 8638 CNRS, Faculté de Pharmacie de Paris, Université Paris Descartes, Sorbonne Paris Cité, \\ 4 Avenue de l'Observatoire, 75006 Paris, France; emmanuel.roulland@parisdescartes.fr (E.R.); \\ olivier.laprevote@parisdescartes.fr (O.L.) \\ 5 Department of Biochemistry, Hôpital Européen Georges Pompidou, AH-HP, 75015 Paris, France \\ * Correspondence: gregory.genta-jouve@parisdescartes.fr; Tel.: +33-173-531-585
}

Received: 30 March 2018; Accepted: 19 May 2018; Published: 22 May 2018

\begin{abstract}
Re-investigation of the chemical composition of the annual plant Mitracarpus scaber Zucc. led to the identification of clarinoside, a new pentalogin derivative containing a rare quinovose moiety, and the known compound harounoside. While the planar structure was fully determined using tandem mass spectrometry (MS) and quantum mechanics (QM) calculations, the tridimensional structure was unravelled after isolation and NMR analysis. The absolute configuration was assigned by comparison of experimental and theoretical synchrotron radiation circular dichroism spectra. Both compounds were tested for anti-inflammatory activity, and compound $\mathbf{1}$ showed the ability to inhibit the production of interleukin-8 (Il-8) with an $\mathrm{IC}_{50}$ value of $9.17 \mu \mathrm{M}$.
\end{abstract}

Keywords: Mitracarpus scaber Zucc.; pentalogin; anti-inflammatory; MS/MS; Il-8

\section{Introduction}

Mass spectrometry (MS) has become a very convenient technique for the targeted search of new bioactive metabolites [1,2], and the recent introduction of the Global Natural Product Social Molecular Networking (GNPS) Web platform (http://gnps.ucsd.edu) has enabled the quick and automatic spectral mining of MS/MS spectra [3]. In our ongoing research for bioactive compounds, we decided to re-investigate the chemical composition of Mitracarpus scaber Zucc. using a MS/MS-guided approach. M. scaber is an annual plant used in African traditional medicine endowed with antifungal, antimicrobial and anti-inflammatory properties [4,5]. Indeed, in West Africa, the leaves of M. scaber are widely used for headache, toothache, amenorrhea, dyspepsia, hepatic diseases, venereal diseases, leprosy, and for the treatment of skin diseases such as scabies, infectious dermatitis, and eczema. It is well known to contain phenols [5], flavonoid glycosides [5], furanocoumarines [5], terpenes [6], alkaloids [7], and pentalongin derivatives [8,9]. Herein, we report the identification of clarinoside (1), a new pentalongin derivative exhibiting the rare quinovose moiety along with the known harounoside (2) (Figure 1). Both compounds were tested for anti-inflammatory activity by evaluating their ability to inhibit the production of interleukin-8 (Il-8). 


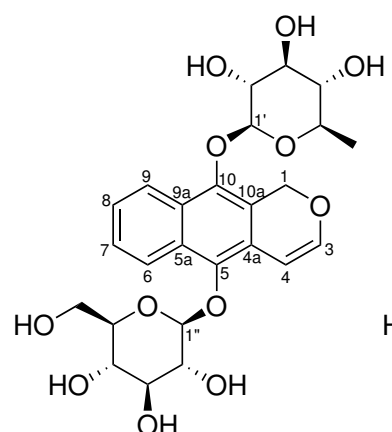

1<smiles>OC[C@H]1O[C@@H](Oc2c3c(c(O[C@H]4O[C@H](CO)[C@H](O)[C@H](O)[C@H]4O)c4ccccc24)COC=C3)[C@H](O)[C@@H](O)[C@@H]1O</smiles>

2

Figure 1. Structures of clarinoside (1) and harounoside (2).

\section{Results}

The analysis started with the creation of a molecular network of the ethanolic extract of $M$. scaber. The data-dependent analysis (DDA) LC-MS/MS data were uploaded to the GNPS platform, and a network was generated using the parameters listed in the Materials and Method section below (Figure 2). As an anchor (reference) compound, harounoside (2) was used. Its node was quickly "illuminated" using the high-resolution MS data and fragmentation pattern. The $m / z$ value at 561.159 corresponding to the $[\mathrm{M}+\mathrm{Na}]^{+}$adduct of 2 was identified, and two diagnostic MS/MS fragments were present on the spectrum (see Supplementary Materials): the first resulting from the cleavage of the glycosidic bond between the aglycone and a glucose moiety at $m / z 399.1080[\mathrm{M}-\mathrm{Glc}+\mathrm{Na}]^{+}$, and the second at $m / z 236.0452$ resulting from the cleavage of the second $\mathrm{O}-\mathrm{C}$ between the aglycone and the other glucose $[\mathrm{M}-2 \mathrm{Glc}+\mathrm{Na}]^{\bullet+}$. In order to find the structurally related compounds, the cluster was further studied by annotating the edges with $m / z$ differences corresponding to known (bio)chemical modifications implemented in the MetaNetter 2 package [10]. Out of the 307 nodes of the network, 1 node directly connected to harounoside (2), with a $m / z$ difference of -15.995 attracting our attention. According to the biotransformation list available in the MetaNetter package, this difference corresponded to a dehydroxylation.

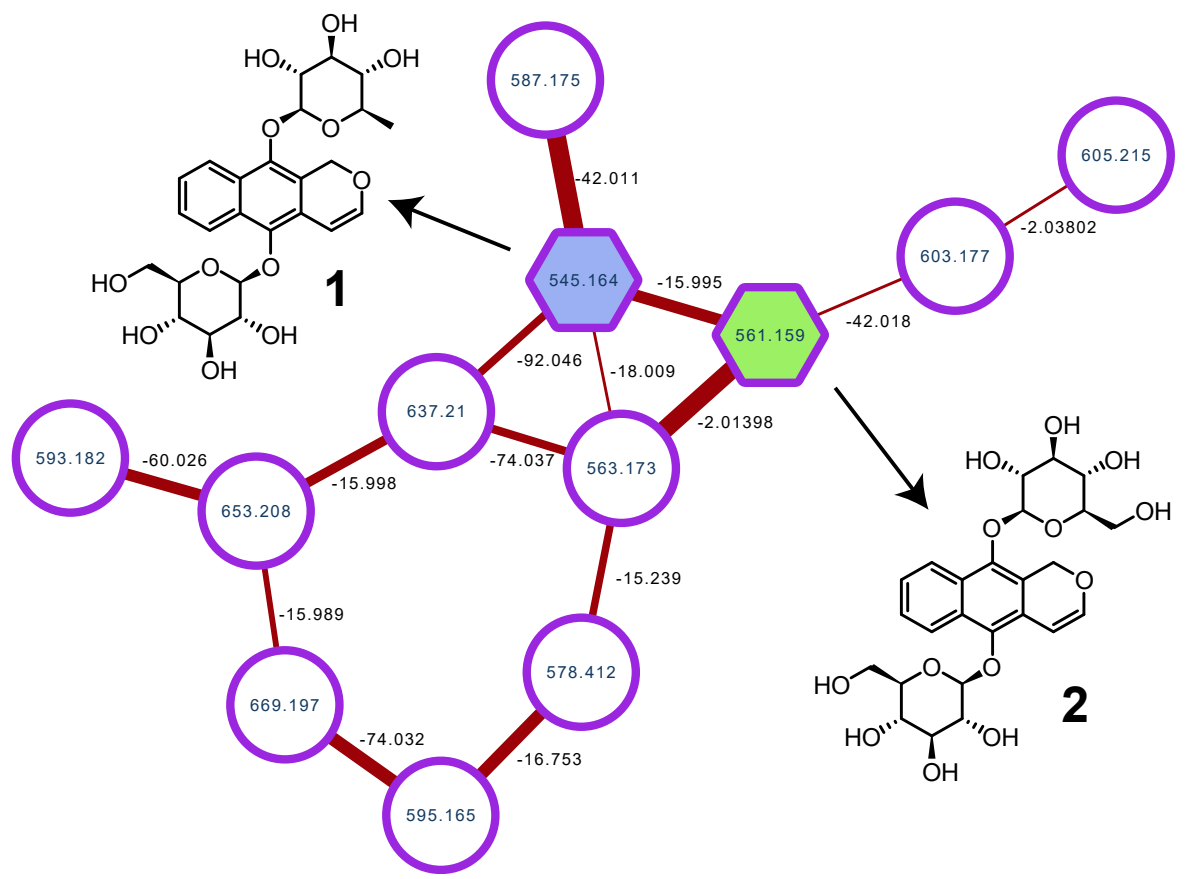

Figure 2. Selected cluster containing clarinoside (1) and harounoside (2). 
Considering the structure of 2 , dehydroxylation could occur at several positions of each of the two sugars; in order to know on which side of the compound 2 the dehydroxylation site was located, the fragmentation of both glucose moieties was studied using quantum mechanics (QM). After examination of the MS/MS spectrum, the sequential losses of two glucoses were observed. The nature of the sugar being the same at C-5 and C-10, the energy level of the two O-C bonds was only related to the position on the aglycone. In order to confirm this hypothesis, the energy profile of the homolytic dissociation was predicted using the B3LYP method at the STO-3G level (see Supplementary Materials). The calculations predicted a difference of ca. $+2.5 \mathrm{eV}$ in favor of the $\mathrm{O}-\mathrm{C}^{\prime \prime}$, indicating that the first fragment observed at $m / z 399.1080$ was related to the loss of one glucose at C-10. This energy difference was very supportive; on the basis of these theoretical results, an energy-resolved mass spectrometry (ERMS) study [11] was undertaken in order to determine the stability of the two $\mathrm{O}-\mathrm{C}$ bonds $\left(\mathrm{O}-\mathrm{Cl}^{\prime \prime}\right.$ and $\left.\mathrm{O}-\mathrm{Cl}^{\prime}\right)$ of compound 2 . After selection of the parent ion at $m / z 561.16$, the intensity of the ion at $m / z 399.11$ was recorded using an increasing value of collision energy (). After the complete extinction of the parent ion (Figure 3A), the daughter ion at $m / z 399.11$ was then fragmented into one major ion at $m / z 185.04$ using the same approach (Figure 3B). As shown in Figure 3, the $\mathrm{O}-\mathrm{Cl}^{\prime}$ bond linking the aglycone to the glucose moiety was weaker than the $\mathrm{O}-\mathrm{C1}^{\prime \prime}$ bond, as it required a lower collision energy value for a $50 \%$ dissociation (ca. 15 and 17 for $\mathrm{O}^{-} \mathrm{C}^{\prime}$ and $\mathrm{O}-\mathrm{C}^{\prime \prime}$, respectively).
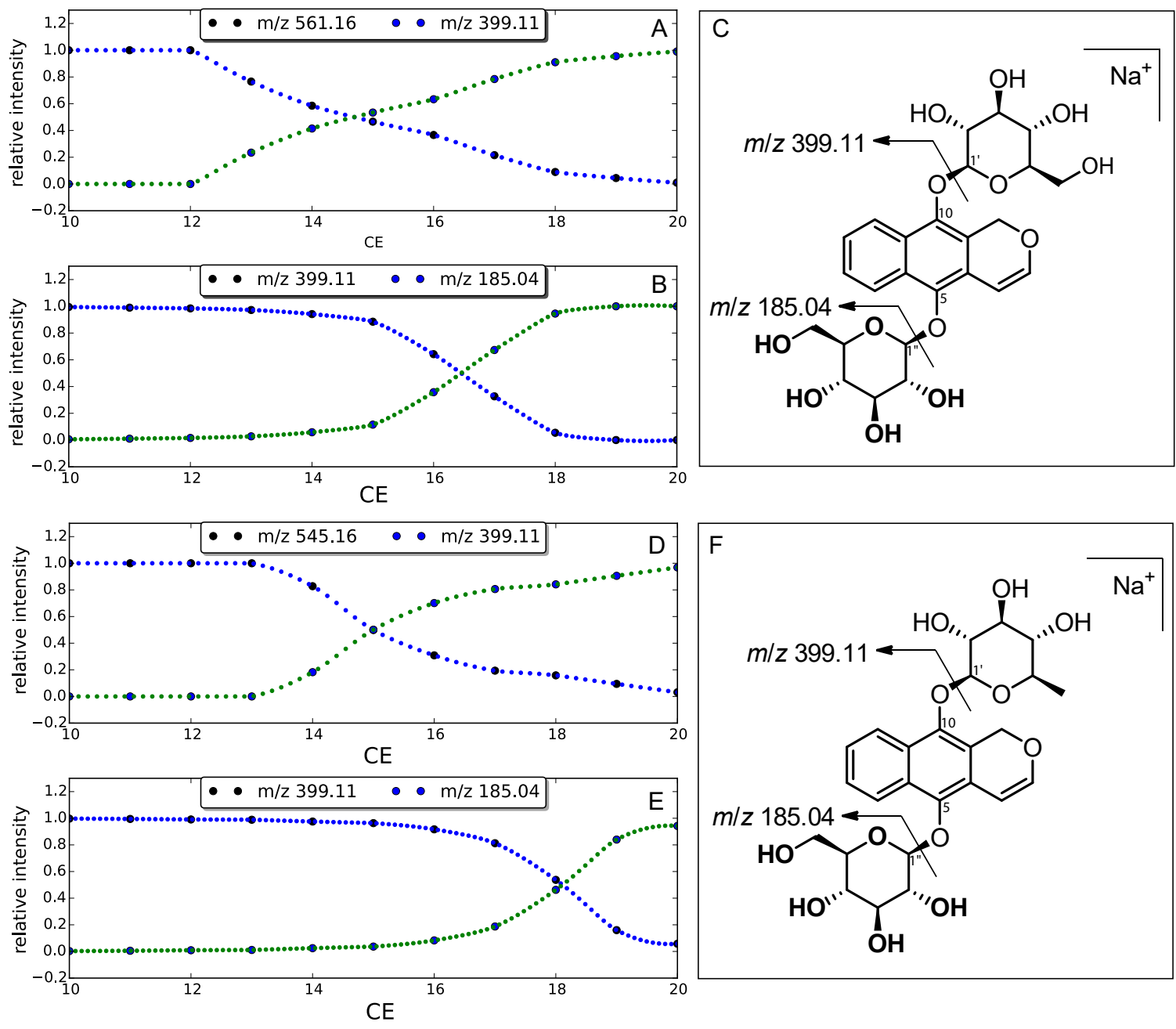

Figure 3. Plot of relative ion current vs collision energy corresponding to $m / z 561.16$ vs. 399.10 (A) and $m / z 399.10$ vs. 185.04 (B). (C) MS/MS fragments of 2 . Plot of relative ion current vs. collision energy corresponding to $m / z 545.16$ vs. 399.10 (D) and $m / z 399.10$ vs. 185.04 (E). (F) MS/MS fragments of 1. 
The experimental data confirmed the QM predicted values, and the same ERMS approach was used for compound 1. As observed in Figure 3D,E, an increase in the collision energy value was required in order to produce the ion at $m / z 185.05$ (ca. 15 and 18 for $\mathrm{O}-\mathrm{C}^{\prime}$ and $\mathrm{O}-\mathrm{C}^{\prime \prime}$, respectively). These results clearly confirmed the position of the deoxyhexose moiety at $\mathrm{C}-10$. The planar structure was further confirmed by the identification of the neutral loss of 146.0605 Da resulting from the difference between the $[\mathrm{M}+\mathrm{Na}]^{+}$ion at $m / z 545.1685$ and the fragment at $m / z$ 399.1080. In parallel with the loss of 162.05 Da corresponding to a glucose moiety (observed for 2), the loss of 146.0605 was consistent with a deoxyhexose such as fucose, rhamnose, or quinovose. Unfortunately, and despite the use of a recent methodology to distinguish the mono-saccharides using MS/MS [12], it was not possible to determine the relative stereochemistry of the sugar moieties using MS analysis only; thus the isolation of compound $\mathbf{1}$ was undertaken.

After a reverse-phase high-performance liquid chromatography (HPLC) purification, $84 \mathrm{mg}$ of compound 1 was obtained, and a full set of NMR experiments was performed. The structure of the aglycone was confirmed by comparison of the ${ }^{1} \mathrm{H}$ and ${ }^{13} \mathrm{C}$ NMR chemical shifts (see Table 1 ). The nature of the sugar was determined by taking advantage of the newly published methodology by Giner et al. [13], which is based on the acid-promoted hydrolysis of the studied compound performed directly in the deuterated NMR solvent. Looking at the ${ }^{1} \mathrm{H}$ NMR spectrum, the doublets at $\delta$ $4.66(\mathrm{~J}=7.7 \mathrm{~Hz})$ and $4.79(\mathrm{~J}=7.8 \mathrm{~Hz})$ ppm clearly confirmed a glucose and a quinovose moiety (see Supplementary Materials). According to the ERMS data, the quinovose was located at C-10, and this was confirmed by the two ${ }^{3} J$ coupling between $\mathrm{H}-1^{\prime} / \mathrm{C}-10$ and $\mathrm{H}-\mathrm{1}^{\prime \prime} / \mathrm{C}-5$ on the HMBC spectrum. The detailed NMR data are given in the Table 1.

Table 1. ${ }^{1} \mathrm{H}$ and ${ }^{13} \mathrm{C}$ NMR data for 1 at $600 \mathrm{MHz}$ in $\mathrm{CD}_{3} \mathrm{OD}\left(\delta_{H}\right.$ in ppm).

\begin{tabular}{|c|c|c|c|c|c|c|c|c|}
\hline \multicolumn{6}{|c|}{ Clarinoside (1) } & \multicolumn{3}{|c|}{ Harounoside (2) [8] } \\
\hline No. & $\delta_{H}($ Multiplicity, $J)$ & $\delta_{C}$ & No. & $\delta_{H}$ (Multiplicity, $J$ ) & $\delta_{C}$ & No. & $\delta_{H}$ & $\delta_{C}$ \\
\hline 1 & $5.29(\mathrm{dd}, 40.7,13.8 \mathrm{~Hz})$ & 65.2 & $1^{\prime}$ & $4.66(\mathrm{~d}, 7.8)$ & 106.2 & 1 & $5.39 ; 5.30$ & 65.4 \\
\hline 3 & $6.67(\mathrm{dd}, 14.4,5.9 \mathrm{~Hz})$ & 147.8 & $2^{\prime}$ & $3.61(\mathrm{dd}, 9.0,7.8)$ & 75.9 & 3 & 6.68 & 147.8 \\
\hline 4 & $6.66(\mathrm{dd} 14.4,5.9 \mathrm{~Hz})$ & 102.1 & $3^{\prime}$ & $3.38(t, 9.0)$ & 77.7 & 4 & 6.64 & 102.2 \\
\hline $4 a$ & & 121.6 & $4^{\prime}$ & $3.11(t, 9.0)$ & 73.5 & $4 a$ & & 121.7 \\
\hline 5 & & 143.3 & $5^{\prime}$ & $3.11(\mathrm{~m})$ & 77.8 & 5 & & 143.4 \\
\hline $5 a$ & & 131.0 & $6^{\prime}$ & $1.21(\mathrm{~d}, 5.4)$ & 18.1 & $5 a$ & & 131.0 \\
\hline 6 & $8.43(\mathrm{~d}, 8.2 \mathrm{~Hz})$ & 124.7 & $1^{\prime \prime}$ & $4.79(\mathrm{~d}, 7.8)$ & 106.9 & 6 & 8.42 & 124.7 \\
\hline 7 & $7.44(\mathrm{dt}, 8.2,1 \mathrm{~Hz})$ & 127.0 & $2^{\prime \prime}$ & $3.65(\mathrm{~m})$ & 75.8 & 7 & 7.43 & 127.0 \\
\hline 8 & $7.40(\mathrm{dt}, 8.2,1 \mathrm{~Hz})$ & 126.2 & $3^{\prime \prime}$ & $3.46(\mathrm{~m})$ & 71.5 & 8 & 7.39 & 126.3 \\
\hline 9 & $8.41(\mathrm{~d}, 8.2 \mathrm{~Hz})$ & 123.7 & $4^{\prime \prime}$ & $3.14(\mathrm{~m})$ & 76.9 & 9 & 8.43 & 123.7 \\
\hline $9 a$ & & 129.1 & $5^{\prime \prime}$ & $3.47(t, 9.0)$ & 78.0 & $9 \mathrm{a}$ & & 129.1 \\
\hline 10 & & 144.9 & $6^{\prime \prime}$ & $3.67(\mathrm{~m})$ & 62.7 & 10 & & 145.0 \\
\hline $10 \mathrm{a}$ & & 122.6 & & & & $10 a$ & & 122.7 \\
\hline
\end{tabular}

The absolute configuration of compound 1 was determined by comparison of a synchrotron radiation circular dichroism (SRCD) spectrum with a time-dependent density functional theory (TD DFT) theoretical electronic circular dichroism (ECD) spectrum (Figure 4). Unexpectedly, the ECD spectrum was quite complex with four Cotton effects of alternative signs. The calculations were run on the four diasteroisomers, that is, D-Glc/D-Qui, D-Glc/L-Qui, L-Glc/D-Qui, and L-Glc/L-Qui. While the absolute D configuration of the glucose moiety was expected, as it is well known that higher plants produce only this enantiomer [14], the absolute configuration of the quinovose moiety was not obvious because the quinovose can originate from either D-glucose [15] or L-fucose [16].

A very good agreement was observed between the D-Glc/D-Qui theoretical and the experimental spectra (Figure 4). Compound 1 could be named as 5,10-dihydroxy-2H-naphtho[2,3-b] -pyran-5- $\beta$-D-glucopyranosyl-10- $\beta$-D-quinovopyranoside. 

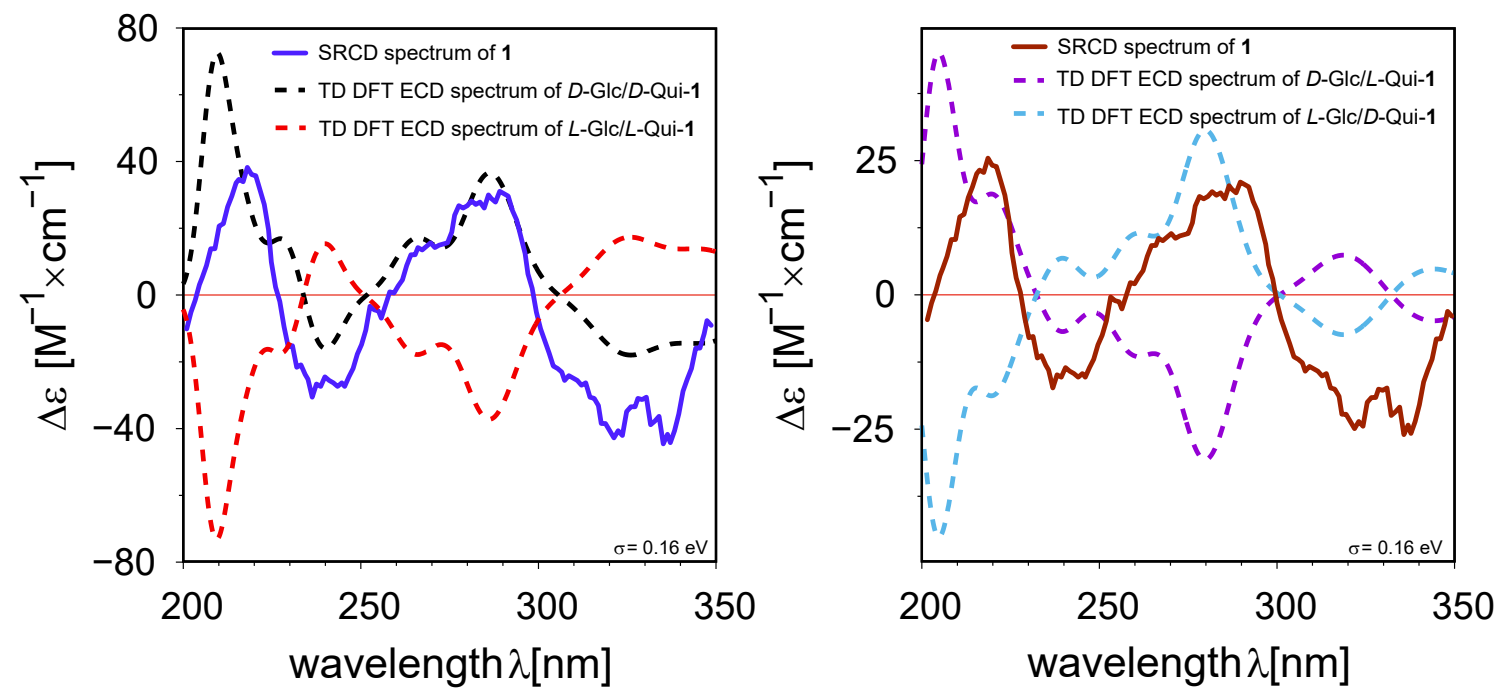

Figure 4. Overlay of synchrotron radiation circular dichroism (SRCD) and TD DFT spectra of 1.

Both compounds $\mathbf{1}$ and $\mathbf{2}$ were tested for anti-inflammatory activity by measuring their ability to inhibit the production of $11-8$, one of the key mediators associated with inflammation [17,18]. After exposure to the tumor necrosis factor alpha (TNF- $\alpha$ ) at $0.5 \mathrm{ng} \cdot \mathrm{mL}^{-1}$ for $24 \mathrm{~h}$, the production of $\mathrm{Il}-8$ was measured and compared to the known anti-inflammatory standard epigallocatechin gallate (EGCG). As shown in Figure 5, the TNF- $\alpha$ induced the production of Il-8 of $398.37 \pm 24.09 \mathrm{pg} / \mathrm{mg}$ of total protein, while the addition of EGCG at $21.8 \mu \mathrm{M}$ allowed a return to the basal threshold of $33.01 \pm 2.12 \mathrm{pg} / \mathrm{mg}$ of total protein.
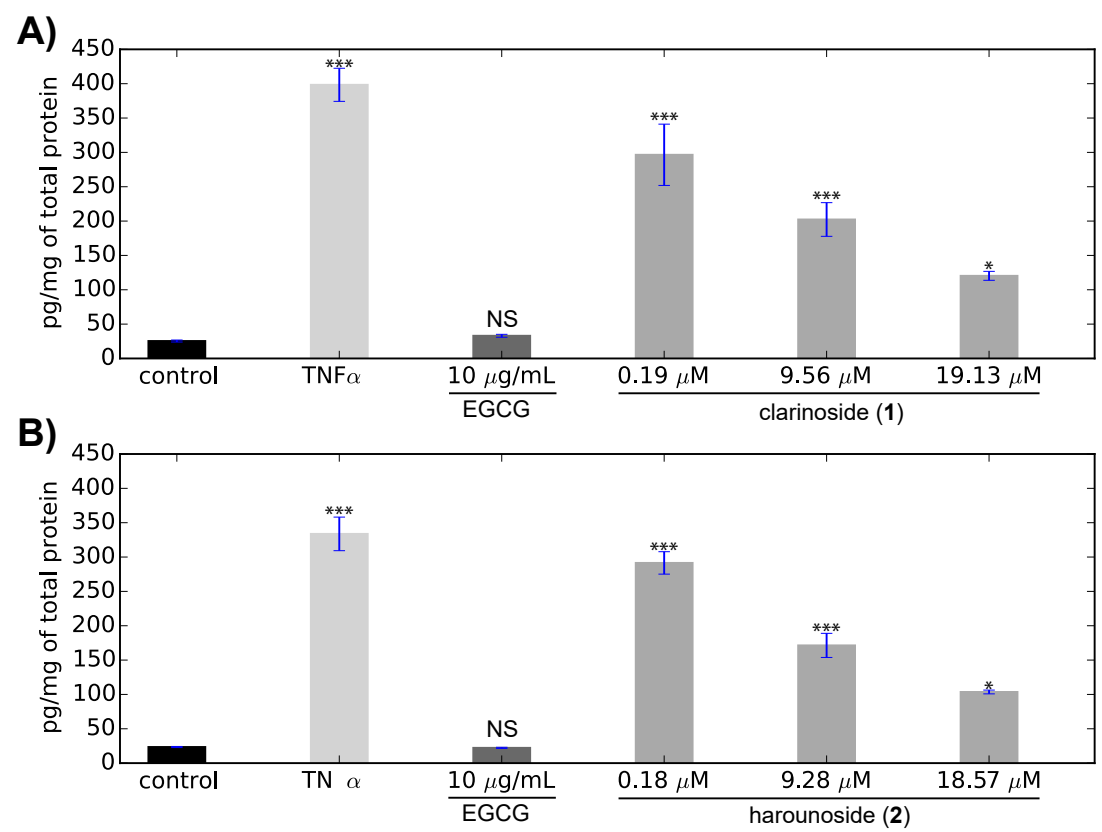

Figure 5. Inhibition of the interleukin-8 (Il-8) production: (A) clarinoside (1); (B) harounoside (2). Means \pm SD are shown. NS: not significant; ${ }^{*} p<0.05 ;{ }^{* * *} p<0.001$.

Although the two compounds were tested during two independent tests, the differences in the measured concentrations (i.e., the production of Il-8 and its inhibition) were observed in both experiments. A good correlation $\left(R^{2}=0.996\right)$ was observed between the inhibition of the production of Il- 8 and the concentration of clarinoside (1). An $\mathrm{IC}_{50}$ value of $9.17 \mu \mathrm{M}$ was measured, and a total 
inhibition of the Il-8 production at $36 \mu \mathrm{M}$ could be extrapolated. The $\mathrm{IC}_{50}$ value of $\mathbf{1}$ was of the same order of magnitude as that of EGCG $(10.9 \mu \mathrm{M}$ [19]), although it was slightly lower. Interestingly, the $\mathrm{IC}_{50}$ value of $2(9.21 \mu \mathrm{M})$ was very similar to that measured for compound $\mathbf{1}$, indicating that the structural modification had no impact on its biological activity.

To conclude, this study enabled the rapid identification of one new compound from M. scaber. The biological activity evaluation highlighted the ability of compounds $\mathbf{1}$ and $\mathbf{2}$ to inhibit the production of Il-8, confirming the importance of M. scaber metabolites and their possible uses in cosmetics and personal care products.

\section{Materials and Methods}

\subsection{General Procedure}

The preparative HPLC was performed on a VWR LaPrep P110 system using a C-630 Büchi UV detector. NMR spectra acquisition was realized using a $600 \mathrm{MHz}$ Bruker Avance spectrometer equipped with Z-gradients and a triple resonance TXI probe. The signals were referenced in ppm to the residual solvent signals $\left(\mathrm{CD}_{3} \mathrm{OD}\right.$, at $\delta_{H} 3.31$ and $\left.\delta_{\mathrm{C}} 49.0\right)$. The infrared spectrum was acquired on a Nicolet IS50 FT-IR spectrophotometer. The specific rotation was measured using an Anton Paar MCP150 polarimeter.

\subsection{Plant Material}

The flowered aerial parts of M. scaber were collected in Burkina Faso in the town of Poun and then dried in the same area.

\subsection{Extraction and Purification}

An ethanolic extraction was performed on a $300 \mathrm{~g}$ sample of the dried plant with a plant/solvent ratio of $1 / 7$ yielding $16.5 \mathrm{~g}$ of crude extract, which was then directly processed by reverse-phase HPLC with an XBridge Prep C18, $5 \mu \mathrm{m}(\mathrm{OBD} 30 \times 250 \mathrm{~mm})$ preparative HPLC column. A gradient $\mathrm{H}_{2} \mathrm{O} / \mathrm{MeOH}$ (from $90 / 10$ to $70 / 30 \mathrm{in} 30 \mathrm{~min}$ at $100 \mathrm{~mL} \cdot \mathrm{min}^{-1}$ ) was used to afford compounds 1 (84 $\mathrm{mg}$ ) and 2 (113 mg).

\subsection{LC-MS Data Acquisition and Processing}

An XEVO-G2 XS QTOF (Waters) equipped with an electrospray ionization (ESI) source was used for the qualitative analysis of the extract. A first screening analysis was performed using the $\mathrm{MS}^{E}$ technology (Waters) on a mass range from 50 to $1500 \mathrm{Da}$. The optimal ionization-source working parameters were as follows: capillary voltage of $3.0 \mathrm{kV}$; sampling cone of $40 \mathrm{~V}$; extraction cone of $6.0 \mathrm{~V}$; source temperature of $150^{\circ} \mathrm{C}$; desolvation temperature of $600{ }^{\circ} \mathrm{C}$; cone gas flow of $50 \mathrm{~L} / \mathrm{h}$; desolvation gas flow of $1000 \mathrm{~L} / \mathrm{h}$. MS/MS data were obtained using a DDA with the same ionization parameters as above using three different collision energies: 10, 20, and $40 \mathrm{~V}$.

\subsection{Construction of the Molecular Network}

A molecular network was created using the online workflow at GNPS [3]. The data were filtered by removing all MS/MS peaks within \pm 17 Da of the precursor $m / z$. MS/MS spectra were window filtered by choosing only the top six peaks in the $\pm 50 \mathrm{Da}$ window throughout the spectrum. The data were then clustered with MS Cluster with a parent mass tolerance of 2.0 Da and a MS/MS fragment ion tolerance of $0.5 \mathrm{Da}$ to create consensus spectra. Furthermore, consensus spectra that contained fewer than two spectra were discarded. A network was then created in which edges were filtered to have a cosine score of above 0.7 and more than three matched peaks. Furthermore, edges between two nodes were kept in the network if and only if each of the nodes appeared in each other's respective top 10 most similar nodes. The spectra in the network were then searched against GNPS's spectral libraries. The library spectra were filtered in the same manner as the input data. All matches kept 
between network spectra and library spectra were required to have a score of above 0.7 and at least six matched peaks.

\subsection{Energy-Resolved Mass Spectrometry}

The LTQ-Orbitrap XL mass spectrometer (Thermo Scientific (Bremen), Bremen, Germany) was used for the ERMS study. The analysis was performed in positive-ion mode with a mass range of $m / z$ 100-1100. The optimized ESI parameters were set as follows: capillary temperature of $250{ }^{\circ} \mathrm{C}$; sheath gas (nitrogen) flow of 30 arb.; auxiliary gas (nitrogen) flow of 10 arb.; source voltage of $4.25 \mathrm{kV}$; capillary voltage of $25 \mathrm{~V}$; tube lens voltage of $110 \mathrm{~V}$. The resolution of the Orbitrap mass analyzer was set at 30,000. The isolation width was $2 \mathrm{amu}$, and the normalized collision energy (CE) was set from 10 to 20. Collision-induced dissociation (CID) was conducted in LTQ with an activation $q$ value of 0.25 and activation time of $30 \mathrm{~ms}$. All instruments were controlled by the Xcalibur data system, and the data acquisition was carried out by analyst software Xcalibur (version 2.1) (Waltham, MA, USA) from Thermo Electron Corp.

\subsection{Synchrotron Radiation Circular Dichroism}

The SRCD experiments were carried out on the SRCD station [20] DISCO beamline [21] at the SOLEIL synchrotron (Gif-sur-Yvette, France). The samples were placed in calcium fluoride cells of 100 micron optical path lengths and measured at $0.2 \mathrm{~mol} / \mathrm{L}$ in methanol. (+)-Camphor-10-sulfonic acid (CSA) solution was used to calibrate the SRCD signal. For each sample, three spectra were collected in the 350-200 nm range with a $1 \mathrm{~nm}$ step and $1200 \mathrm{~ms}$ integration time. The molar circular dichroism $\Delta \epsilon$ is expressed in $\mathrm{M}^{-1} \mathrm{~cm}^{-1}$.

\subsection{Computational Details}

All QM calculations were carried out using Gaussian 16 [22]. The energy scan of the C-O bonds was performed using the Hartree-Fock method at the STO-3G level and a $0.1 \AA$ bond-length step. The GMMX package was used for the conformational analysis (force field: MMFF94). The TD DFT calculations were performed using the B3LYP method at the 6-31G(d) level for 20 excited states. SpecDis 1.71 software was used to plot the ECD spectrum [23].

\subsection{Cell Culture}

HaCaT keratinocyte cells were cultured under standard conditions in DMEM supplemented with $10 \%$ fetal calf serum. The medium was changed every second day. Confluent cultures were removed by trypsin incubation, and then the cells were counted. They were seeded into 96-well culture microplates at a density of 30,000 cells per well $(200 \mu \mathrm{L})$ and kept at $37^{\circ} \mathrm{C}$ for $24 \mathrm{~h}$.

\subsection{Interleukine Release Measurement}

The release of Il-8 in cell supernatants was determined by ELISA. After TNF- $\alpha$ incubation $(0.5 \mathrm{ng} / \mathrm{mL})$, cell supernatants were harvested and stored at $-20{ }^{\circ} \mathrm{C}$ until use for measurements. The quantity of released Il-8 was measured according to the manufacturer's instructions (Kit ELISA Human CXCL8 / IL8 R\&D Systems). The decrease in Il-8 production by EGCG (10 $\mu \mathrm{g} / \mathrm{mL})$ validated the method.

\subsection{Statistical Analyses}

All statistical analyses were performed using R 3.5.0 [24]. Cell samples were analyzed by repeated measures $(n=4)$ one-way analysis of variance (ANOVA) followed by a Tukey's range test. Significant differences for both clarinoside (1) and harounoside (2) were relative to control as indicated (NS: not significant; $\left.{ }^{*} p<0.05 ;{ }^{* * *} p<0.001\right)$. 


\subsection{Compound Characterization}

1: White, amorphous solid; $[\alpha]_{\mathrm{D}}^{20}+12.8$ (c $0.1, \mathrm{CH}_{3} \mathrm{OH}$ ); UV (DAD) $\lambda_{\max } 223,245,284,346 \mathrm{~nm}$; ${ }^{1} \mathrm{H}$ NMR and ${ }^{13} \mathrm{C}$ NMR data: see Table 1 ; HRESIMS $(+) m / z 545.1685[\mathrm{M}+\mathrm{Na}]^{+}(545,16295$ calcd. for $\left.\mathrm{C}_{25} \mathrm{H}_{30} \mathrm{O} 12 \mathrm{Na}, \Delta-1.8 \mathrm{ppm}\right)$.

Supplementary Materials: Supplementary materials, including HRMS, 1D and 2D NMR spectra for compound $\mathbf{1}$, and computational details for 2 , are available online.

Author Contributions: G.G.-J. and C.A. conceived and designed the experiments; C.A., A.Z., N.B., E.R., and G.G.-J. performed the experiments; C.A., O.L., and G.G.-J. analyzed the data; A.G. and E.R. contributed reagents, materials, and analysis tools; all the authors wrote the paper.

Acknowledgments: SOLEIL support is acknowledged under Proposal No. 20170521. We also thank the technical staff of SOLEIL for smooth and efficient running of the facility. The authors are grateful to Pascale Leproux and Karim Hammad for MS and NMR spectra recording. The Région Île de France is also acknowledged for its support through the funding of the DIM Analytics Project PRIMEVEGE (ANA2014-ML-001).

Conflicts of Interest: The authors declare no conflict of interest.

\section{References and Notes}

1. Olivon, F.; Allard, P.M.; Koval, A.; Righi, D.; Genta-Jouve, G.; Neyts, J.; Apel, C.; Pannecouque, C.; Nothias, L.F.; Cachet, X.; et al. Bioactive Natural Products Prioritization Using Massive Multi-informational Molecular Networks. ACS Chem. Biol. 2017, 12, 2644-2651. [CrossRef] [PubMed]

2. Nothias, L.F.; Nothias-Esposito, M.; da Silva, R.; Wang, M.; Protsyuk, I.; Zhang, Z.; Sarvepalli, A.; Leyssen, P.; Touboul, D.; Costa, J.; et al. Bioactivity-Based Molecular Networking for the Discovery of Drug Leads in Natural Product Bioassay-Guided Fractionation. J. Nat. Prod. 2018, 81, 758-767. [CrossRef] [PubMed]

3. Wang, M.; Carver, J.J.; Phelan, V.V.; Sanchez, L.M.; Garg, N.; Peng, Y.; Nguyen, D.D.; Watrous, J.; Kapono, C.A.; Luzzatto-Knaan, T.; et al. Sharing and community curation of mass spectrometry data with Global Natural Products Social Molecular Networking. Nat. Biotechnol. 2016, 34, 828-837. [CrossRef] [PubMed]

4. Ekpendu, T.O.; Akah, P.A.; Adesomoju, A.A.; Okogun, J.I. Antiinflammatory and Antimicrobial Activities of Mitracarpus scaber Extracts. Int. J. Pharmacogn. 1994, 32, 191-196. [CrossRef]

5. Bisignano, G.; Sanogo, R.; Marino, A.; Aquino, R.; D'angelo, V.; Germano, M.P.; De Pasquale, R.; Pizza, C. Antimicrobial activity of Mitracarpus scaber extract and isolated constituents. Lett. Appl. Microbiol. 2000, 30, 105-108. [CrossRef] [PubMed]

6. Gbaguidi, F.; Accrombessi, G.; Moudachirou, M.; Quetin-Leclercq, J. HPLC quantification of two isomeric triterpenic acids isolated from Mitracarpus scaber and antimicrobial activity on Dermatophilus congolensis. J. Pharm. Biomed. Anal. 2005, 39, 990-995. [CrossRef] [PubMed]

7. Okunade, A.L.; Clark, A.M.; Hufford, C.D.; Oguntimein, B.O. Azaanthraquinone: An Antimicrobial Alkaloid from Mitracarpus scaber. Planta Med. 1999, 65, 447-448. [CrossRef] [PubMed]

8. Harouna, H.; Faure, R.; Elias, R.; Debrauwer, L.; Saadou, M.; Balansard, G.; Boudon, G. Harounoside a pentalongin hydroquinone diglycoside from Mitracarpus scaber. Phytochemistry 1995, 39, 1483-1484. [CrossRef]

9. Pialat, J.P.; Hoffmann, P.; Moulis, C.; Fouraste, I.; Labidalle, S. Synthesis and Extraction of Pentalongin, A Naphthoquinoid From Mitracarpus Scaber. Nat. Prod. Lett. 1998, 12, 23-30. [CrossRef]

10. Burgess, K.; Borutzki, Y.; Rankin, N.; Daly, R.; Jourdan, F. MetaNetter 2: A Cytoscape plugin for ab initio network analysis and metabolite feature classification. J. Chromatogr. B 2017, 1071, 68-74. [CrossRef] [PubMed]

11. Menachery, S.P.M.; Laprévote, O.; Nguyen, T.P.; Aravind, U.K.; Gopinathan, P.; Aravindakumar, C.T. Identification of position isomers by energy-resolved mass spectrometry. J. Mass Spectrom. 2015, 50, 944-950. [CrossRef] [PubMed]

12. Xia, B.; Zhou, Y.; Liu, X.; Xiao, J.; Liu, Q.; Gu, Y.; Ding, L. Use of electrospray ionization ion-trap tandem mass spectrometry and principal component analysis to directly distinguish monosaccharides. Rapid Commun. Mass Spectrom. 2012, 26, 1259-1264. [CrossRef] [PubMed] 
13. Giner, J.L.; Feng, J.; Kiemle, D.J. NMR Tube Degradation Method for Sugar Analysis of Glycosides. J. Nat. Prod. 2016, 79, 2413-2417. [CrossRef] [PubMed]

14. Genta-Jouve, G.; Weinberg, L.; Cocandeau, V.; Maestro, Y.; Thomas, O.P.; Holderith, S. Revising the Absolute Configurations of Coatlines via Density Functional Theory Calculations of Electronic Circular Dichroism Spectra. Chirality 2013, 25, 180-184. [CrossRef] [PubMed]

15. Han, A.R.; Park, S.R.; Park, J.W.; Lee, E.Y.; Kim, D.M.; Kim, B.G.; Yoon, Y.J. Biosynthesis of Glycosylated Derivatives of Tylosin in Streptomyces venezuelae. J. Microbiol. Biotechnol. 2011, 21, 613-616. [CrossRef] [PubMed]

16. De Castro, C.; Kenyon, J.J.; Cunneen, M.M.; Molinaro, A.; Holst, O.; Skurnik, M.; Reeves, P.R. The O-specific polysaccharide structure and gene cluster of serotype O:12 of the Yersinia pseudotuberculosis complex, and the identification of a novel l-quinovose biosynthesis gene. Glycobiology 2013, 23, 346-353. [CrossRef] [PubMed]

17. Baggiolini, M.; Clark-Lewis, I. Interleukin-8, a chemotactic and inflammatory cytokine. FEBS Lett. 1992, 307, 97-101. [CrossRef]

18. Pease, J.E.; Sabroe, I. The Role of Interleukin-8 and its Receptors in Inflammatory Lung Disease. Am. J. Respir. Med. 2002, 1, 19-25. [CrossRef] [PubMed]

19. This concentration of EGCG has been measured on a previous experiment.

20. Réfrégiers, M.; Wien, F.; Ta, H.P.; Premvardhan, L.; Bac, S.; Jamme, F.; Rouam, V.; Lagarde, B.; Polack, F.; Giorgetta, J.L.; et al. DISCO synchrotron-radiation circular-dichroism endstation at SOLEIL. J. Synchrotron Radiat. 2012, 19, 831-835. [CrossRef] [PubMed]

21. Giuliani, A.; Jamme, F.; Rouam, V.; Wien, F.; Giorgetta, J.L.; Lagarde, B.; Chubar, O.; Bac, S.; Yao, I.; Rey, S.; et al. DISCO: A low-energy multipurpose beamline at synchrotron SOLEIL. J. Synchrotron Radiat. 2009, 16, 835-841. [CrossRef] [PubMed]

22. Frisch, M.J.; Trucks, G.W.; Schlegel, H.B.; Scuseria, G.E.; Robb, M.A.; Cheeseman, J.R.; Scalmani, G.; Barone, V.; Petersson, G.A.; Nakatsuji, H.; et al. Gaussian 16 Revision B.01; Gaussian Inc.: Wallingford, CT, USA, 2016.

23. Bruhn, T.; Schaumlöffel, A.; Hemberger, Y.; Bringmann, G. SpecDis: Quantifying the Comparison of Calculated and Experimental Electronic Circular Dichroism Spectra. Chirality 2013, 25, 243-249. [CrossRef] [PubMed]

24. R Core Team. R: A Language and Environment for Statistical Computing; R Foundation for Statistical Computing: Vienna, Austria, 2018.

Sample Availability: Samples of the compounds $\mathbf{1}$ and $\mathbf{2}$ are available from the authors.

(C) 2018 by the authors. Licensee MDPI, Basel, Switzerland. This article is an open access article distributed under the terms and conditions of the Creative Commons Attribution (CC BY) license (http:// creativecommons.org/licenses/by/4.0/). 